\title{
Pursuing a Career in Clinical Psychology: A Review
}

\author{
Mina Khatibi ${ }^{1}$
}

Keywords: Career, clinical psychology

Clinical psychology is a branch of psychology devoted to understanding mental health problems in individuals and developing effective treatments for the full spectrum of mental, emotional, and behavioral disorders one may experience; depression, anxiety disorders, interpersonal difficulties, and psychotic disorders are but a few. Clinical psychologists are service providers, many of whom work in clinical settings while others choose academic careers or careers in consulting. As a group, clinical psychologists are skilled in clinical practice as well as research on clinical problems and clinical interventions (University of Glasgow, 2014).

While they often work in medical settings, clinical psychologists are not medical doctors and do not prescribe medications in most states. Clinical psychology represents the largest subfield of psychologists. Specialty areas within clinical psychology include child mental health, adult mental health, learning disabilities, emotional disturbances, substance abuse, geriatrics, and health psychology (Cherry, 2015).

Most clinical psychologists have a doctorate degree in clinical psychology, although opportunities also exist for those with a master's degree (Cherry, 2014).Before committing yourself to pursuing a career in clinical psychology, it is essential to consider a number of important points which should help as you think about graduate training and help you to better plan for a career in clinical psychology (University of Glasgow, 2014).

\section{HISTORY OF CLINICAL PSYCHOLOGY}

By the second half of the 1800s, the scientific study of psychology was becoming wellestablished in university laboratories. Although there were a few scattered voices calling for an applied psychology, the general field looked down upon this idea and insisted on "pure" science as the only respectable practice. This changed when Lightner Witmer (1867-1956), a past student of Wundt and head of the psychology department at the University of Pennsylvania, agreed to treat a young boy who had trouble with spelling.

His successful treatment was soon to lead to Witmer's opening of the first psychological clinic at Penn in 1896, dedicated to helping children with learning disabilities.

\footnotetext{
${ }^{1}$ PhD Student, Department of Educational Psychology, Shiraz University, UAE Blaıuı, 上uиa, чль (C) 2015 I M Khatibi; licensee IJIP. This is an Open Access Research distributed under the terms of the Creative Commons Attribution License (http://creativecommons.org/licenses/by/2.0), which permits unrestricted use, distribution, and reproduction in any Medium, provided the original work is properly cited.
} 
Ten years later in 1907, Witmer was to found the first journal of this new field, The Psychological Clinic, where he coined the term "clinical psychology," which he defined as "the study of individuals, by observation or experimentation, with the intention of promoting change." The field was slow to follow Witmer's example, but by 1914, there were 26 similar clinics in the U.S.(Alessandri, et al., 1995).

Although his ideas were somewhat slow to catch on, Witmer is now credited with being one of the founding fathers of clinical psychology. His progress in treating that one child helped pave the way for the future of clinical psychology (Careersinpsychology.org., 2015).

\section{What Does A Clinical Psychologist Do?}

Clinical psychologists often work in hospitals, private practice, or academic settings. Clinicians are trained in a range of techniques and theoretical approaches. Some specialize in treating certain psychological disorders, while others work with clients suffering from a wide variety of problems. Clinical psychologists treat some of the most severe psychiatric disorders such as schizophrenia and depression. In addition to working with clients, clinical psychologists have to keep detailed records of client assessment, diagnosis, therapeutic goals, and treatment notes. These records help clinicians and clients track progress and are often needed for billing and insurance purposes (Cherry, 2015).

\section{Job Responsibilities for Clinical Psychologist:}

1. Assessing and diagnosing a client's psychological functioning and behavior using direct observation, interviews, and psychometric tests.

2. Developing a course of therapy using empirically supported (or scientifically valid) psychological treatments for clients.

3. Working in conjunction with other healthcare professionals to ensure the best course of treatment for a client's needs.

4. Treating psychological disorders using various psychological techniques, such as cognitive therapy, behavioral treatment, stress inoculation training, anxiety management, and exposure therapy.

5. Conducting applied research for the development and validation of assessments and interventions, and for program evaluation (Clinical psychologist, 2015).

\section{A Career In Clinical Psychology Requires:}

1. Excellent communication skills.

2. Skill in the analysis of personal problems and individual needs.

3. An understanding of the influence of feelings, attitudes, thoughts, and perspectives on the behavior of others.

4. An understanding of ethical principles, of diversity, and of cultural context.

5. The ability to lead, inspire, and work effectively with people.

6. Personal integrity and a commitment to behave ethically.

7. An active concern for the welfare of others.

8. Recognition of the need for competence and continuous learning.

9. An ability to be non-judgmental and objective (Clinical psychologist, 2015). 


\section{What are the Education Requirements to become a Clinical Psychologist?}

In many parts of the U.S. those who provide psychological services to the public are required to have a doctoral degree. This can be either a PhD or a PsyD, but it should be from a program that is accredited by the American Psychological Association. Most states will only issue licenses to those who have completed accredited programs. In some places you can practice with only a master's degree, but often must work under the supervision of a doctoral level psychologist. Coursework may include, depending on the degree, classes in neuropsychology, ethics, social psychology, psychopathology, psychotherapy, statistics, and research design. Students also must spend time getting practical experience. In clinical psychology programs, for example, students treat clients under the supervision of a licensed psychologist (McKay, 2015).

While some individuals find work with a master's degree, most positions require a doctoral degree in clinical psychology. Some graduate programs accepts applicants with undergraduate degrees in other disciplines, but most encourage students to get a bachelor's degree in psychology before pursuing graduate study in clinical psychology(Cherry, 2015).

There are two major training models for doctoral degrees. The traditional $\mathrm{PhD}$ in Psychology (or Doctor of Philosophy in Psychology) emphasizes the role of the research and science. The PsyD degree (Doctor of Psychology) is primarily focused on clinical and practitioner work. PsyD programs are attractive to many students because they typically take approximately a year less time to complete than a $\mathrm{PhD}$. On the other hand, $\mathrm{PhD}$ programs tend to provide better funding of graduate students (Cherry, 2015).

Average length of study for various degrees in clinical psychology.

\begin{tabular}{|l|l|}
\hline Psychologist educational track & Average education length \\
\hline Earn a bachelor's degree & 4 years \\
\hline Earn a master's degree & 2 additional years \\
\hline Earn a PhD or PsyD & $2-4$ additional years \\
\hline
\end{tabular}

As with all other psychology careers, becoming a clinical psychologist requires extensive training and education. In order to start a clinical psychology career, individuals will typically need to earn a bachelor's in psychology or clinical psychology. Additional schooling is also usually necessary after the four- year degree. This typically includes earning a master's degree and doctoral degree in clinical psychology (Careersinpsychology.org., 2015). 


\section{WHAT DO CLINICAL PSYCHOLOGISTS STUDY?}

\section{Required courses for a doctorate in clinical psychology typically include:}

1. History.

2. Theory and systems in psychology.

3. Psychometrics.

4. Psychological assessment.

5. Psychological interventions.

6. A doctoral seminar.

7. Students must also complete two practicums in clinical psychology and one year as an intern before obtaining a $\mathrm{PhD}$ (Clinical psychologist, 2015).

\section{Does It Require Internship?}

For clinical and counseling psychologists, a doctorate in psychology is usually required. In addition to the doctorate degree, an approved internship and one to two years of professional experience is also needed. All states also require that applicants pass an examination. In most states, the examination consists of a standardized test administered by the state licensing board. In some cases, applicants are also required to complete additional oral or essay questions. Some states require continuing education for renewal of the license (McKay, 2015).

\section{What Types of Treatments are used in Clinical Psychology?}

Clinical psychologists typically don't use medication to treat disorders. If medication is needed for a particular disorder, the patient will usually be referred to another mental health professional, such as a psychiatrist.

Different types of therapy are usually used as treatment options in clinical psychology instead. This can include cognitive behavioral therapy, family therapy, group therapy, and hypnotherapy. These types of therapies focus more on talking through one's problems and trying to figure out better ways to handle life’s hurdles (Careersinpsychology.org., 2015).

\section{Where could a Clinical Psychologist Work?}

1. Regional health authorities such as hospitals, mental health clinics, and psychiatric and rehabilitation centers.

2. Private practice.

3. Universities and colleges.

4. Industry.

5. The military.

6. Prisons and correctional facilities.

7. Research agencies.

8. Schools.

9. Government (Clinical psychologist, 2015). 


\section{Pursuing a Career in Clinical Psychology: A Review}

\section{Licensing Requirement:}

Psychologists who deliver patient care must meet certification or licensing requirements in all states. It is important to check the licensing requirements in the state in which you want to work to find out which type of degree you need to pursue (McKay, 2015).

\section{Job outlook:}

Clinical psychology is a growing field, and the demand for clinical psychologists in the U.S. is expected to increase from 2010 through 2020. The government predicts a 22\% increase, which is faster than the average rate of job growth, for a total of 37,700 jobs added during those ten years (McKay, 2015).

\section{Employment fact:}

Psychologists held about 174,000 jobs in 2010. There were 154,000 clinical, counseling, and school psychologists, 2,000 industrial-organizational psychologists, and 18,000 who were employed in other specializations.

Since clinical psychologists must be available when their clients can see them, many work in the evenings and on weekends. Those who have private practices can work part-time if they wish. Clinical psychologists need to have excellent communication skills. It is also important to be creative when developing treatment plans and approaches. Before you decide on a career in clinical psychology, contact local human services providers about volunteer opportunities that may be available. Clinical psychology can be both a demanding and deeply rewarding field and volunteer experiences can help you decide if a career in clinical psychology is right for you(McKay, 2015).

\section{WHAT ARE THE PROS AND CONS OF A CAREER IN CLINICAL PSYCHOLOGY?}

\section{Benefits of a career in clinical psychology:}

- Helping people overcome problems can be extremely rewarding.

- Differing client needs and challenges allow clinicians to search for creative solutions.

- Opportunities for self-employment.

\section{Downsides of a career in clinical psychology:}

- Insurance companies require that clinical psychologists keep extensive client records, so there is a considerable amount of paperwork.

- There is a risk of burnout due to the demanding nature of therapy.

- Clinical psychologists often work long hours with clients who can be demanding, argumentative, or unstable(Cherry, 2015).

\section{How much do clinical psychologists earn?}

According to the American Psychology Association Research Office, in 2001 the average salary for a licensed clinical psychologist was $\$ 72,000$. Of the psychologists surveyed, $65 \%$ worked in private practice, $19 \%$ worked in medical settings, and $2 \%$ worked in some other human services setting. 
The U. S. Department of Labor's Occupational Outlook Handbook reports that employment in psychology is expected to grow faster than the average. The rising need for qualified mental healthcare professionals will contribute to a demand for clinical psychologists(Cherry, 2015).

In a 2000 survey by the American Psychological Association, the average salary for a licensed clinical psychologist was $\$ 87,015$. Out of the surveyed psychologists, $15 \%$ worked in group medical settings, $57 \%$ worked in private practice, and $2 \%$ were employed in some other human services setting.

According to Payscale.com, typical salaries for clinical psychologists range between $\$ 51,885$ and $\$ 90,330$. However, it is important to note that several different factors can impact the salary you might expect including level of education, years of experience, work setting, and geographic location. For example, for clinical psychologist working in private practice with five years of experience, the average salary in 2009 was $\$ 54,000$. For those with 10 to 14 years of experience, the average wage was nearly $\$ 100,000$ (Grove, 2015).In 2011, salaried clinical, counseling, and school psychologists in the U.S. earned a median annual salary of $\$ 67,880$ (\$32.64 per hour).

According to the U.S. Bureau of Labor Statistics:

- Psychologists can expect faster-than-average job growth, as much as 15\% through 2016.

- As of 2006, about $34 \%$ of psychologists were self-employed.

- Offices of mental health practitioners, hospitals, physicians' offices, and outpatient mental health and substance abuse centers employ about $21 \%$ of psychologists.

- Nearly $29 \%$ of psychologists are employed to provide counseling, testing, research, and administration within educational institutions.

- An increasing number of employee assistance programs, which help workers deal with personal problems, also should lead to employment growth for clinical psychologists(Grove, 2015).

\section{What are the differences between PhD, PsyD, and Counseling Psychology?}

$\mathrm{PhD}$ programs are housed in psychology departments and emphasize both research training and clinical training. They require that students conduct independent empirical research to complete the degree requirements. People with $\mathrm{PhDs}$ in clinical psychology are eligible to apply for jobs in research, teaching, and clinical practice. As such, their employment opportunities are broader than those of PsyDs. In PsyD programs, the emphasis is on training clinical practitioners. Such programs are usually less competitive than $\mathrm{PhD}$ programs and place less emphasis on the scientific basis of clinical psychology(University of Columbia, 2015).

\section{What are the differences between Psychiatry and Clinical Psychology?}

Psychiatrists are medical doctors who acquire specialized training in the field of psychiatry. Preparation for being a psychiatrist involves (a) completing undergraduate pre-med courses, (b) completing medical school (four years) and a one-year medical internship, and (c) a residency in 
psychiatry. The main difference between what psychiatrists and psychologists can do is that psychiatrists can prescribe drugs. The majority of psychiatric residencies emphasize the biological basis of mental illness and psychiatrists tend to focus on drug-related treatments of mental illness. Psychologists engage in a variety of kinds of talk therapy. Often psychiatrists and psychologists work together to treat people with a mental illness(University of Columbia, 2015).

\section{Completing a PhD/PsyD program}

Most clinical PhD programs take five to six years to complete. An additional year is spent doing a clinical internship. This is usually in a hospital or mental health center and is intended to provide experience with a range of clinical work. After internship, additional supervised clinical work is needed to become licensed as a clinical psychologist. PsyD and counseling psychologists who also complete an internship and the other requirements of licensing can get a license. In addition to the degree and the clinical experience, candidates for a license must pass an exam(University of Columbia, 2015).

\section{CONCLUSION}

You will most likely apply to several programs perhaps with some variation in terms of how selective they are. But, in general, apply to those which you have some reasonable chance of admission. Consider the question: Would this be a good place for me to study, if I am offered admission? Again, applying to graduate training in clinical psychology is a long-term commitment and this kind of planning takes time. Start your search as soon as possible. It can be fun as well as informative(University of Glasgow, 2014).

\section{How to become a clinical psychologist (10 steps)?}

The road to becoming a clinical psychologist is a long and hard one and only the most dedicated students succeed. Graduate programs in clinical psychology are competitive and accept only the best of the best. You must make it through one of these programs and get through another two years of training before you can become a licensed clinical psychologist(Barratt C, et al., 2015).

1. Finish your high school courses with at least a 3.0 grade point average (GPA).

2. Enroll in an undergraduate psychology program at an accredited university of your choice.

3. Participate in research projects, internships, and teaching assistant programs as much as possible.

4. Join psychology clubs and stay active with them.

5. Start shopping around for a grad program in clinical psychology.

6. Apply to any programs that appeal to you. Submit everything that the school asks for by the deadline.

7. Study hard once you enter your clinical psychology graduate program.

8. Complete your post-doctoral training with a licensed clinical psychologist.

9. Fill out the application for a state clinical psychology license and submit any associated fees.

10. Set up your new practice or discuss staying at your post-doctoral supervisor's practice. 


\section{REFERENCES}

Alessandri, M., Heiden, L., Dunbar-Welter, M. (1995). "History and overview". In: Heiden, L. \& Hersen, M. (Eds). Introduction to Clinical Psychology. New York, NY: Plenum Press. pp. 3-19.

Barratt C, et al. (2015). How to become a clinical psychologist, wikiHow. http://www.wikihow.com/Become-a-Clinical-Psychologist.

Careersinpsychology.org. (2015). How to become a psychologist? Clinical psychologist careers, education requirements, salary, information.http://careersinpsychology.org/becoming-aclinical-psychologist.

Cherry, K. (2014). Have you considered a career in psychology? About.com Guide. http://psychology.about.com/od/careersinpsychology/ss/become-a-psychologist.htm.

Cherry, K. (2015). Career in psychology. Clinical psychology careers, About.com Guide, http://psychology.about.com/od/psychologycareerprofiles/p/clinicalpsych.htm.

Clinical psychologist. (2015). Career profile, Saskatchewan Health, Saskatchewan learning,m.therapists.psychologytoday.com/...Saskatchewan.html.

Grove, D. (2015). Clinical psychology as a career, Midwestern University, midwestern.edu/.../il-clinical-psychology.html.

McKay, D.R. (2015). Psychologist: Career information, About.com Guide,careerplanning.about.com/... ations/p/psychologist.htm.

University of Columbia. (2015). Preparing for a career in clinical psychology. Department of Psychology at University of Columbia, http://www.tc.columbia.edu/academic/ccp/clinical/.

University of Glasgow. (2014). So, you want to become a clinical psychologist. Department of Psychology,www.psy.gla.ac.uk/docs/pdfs/BPS_careers_guides.pdf. 